
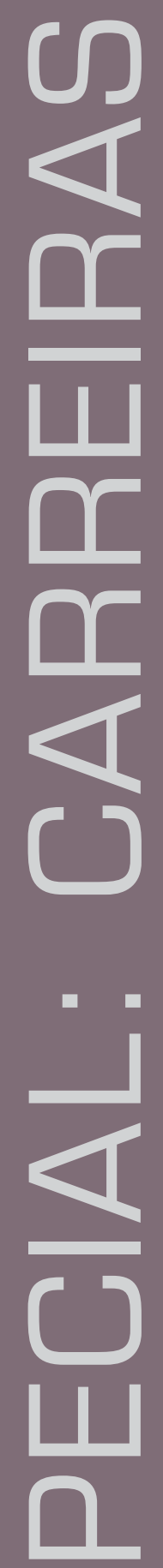

$\mathcal{O}$

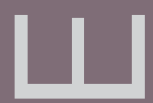

44 | VOL.7 | No1 | JAN/FEV 2008
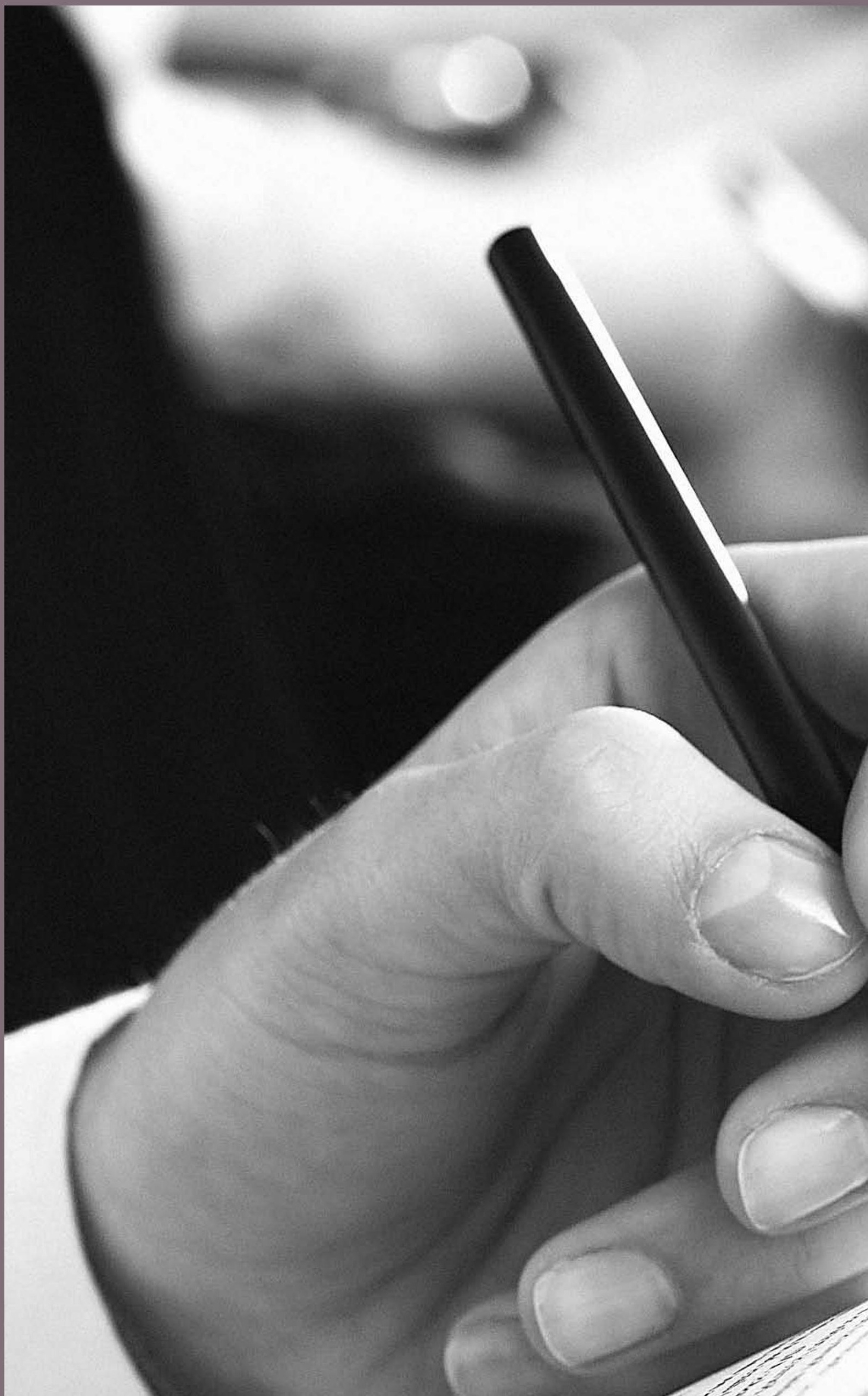

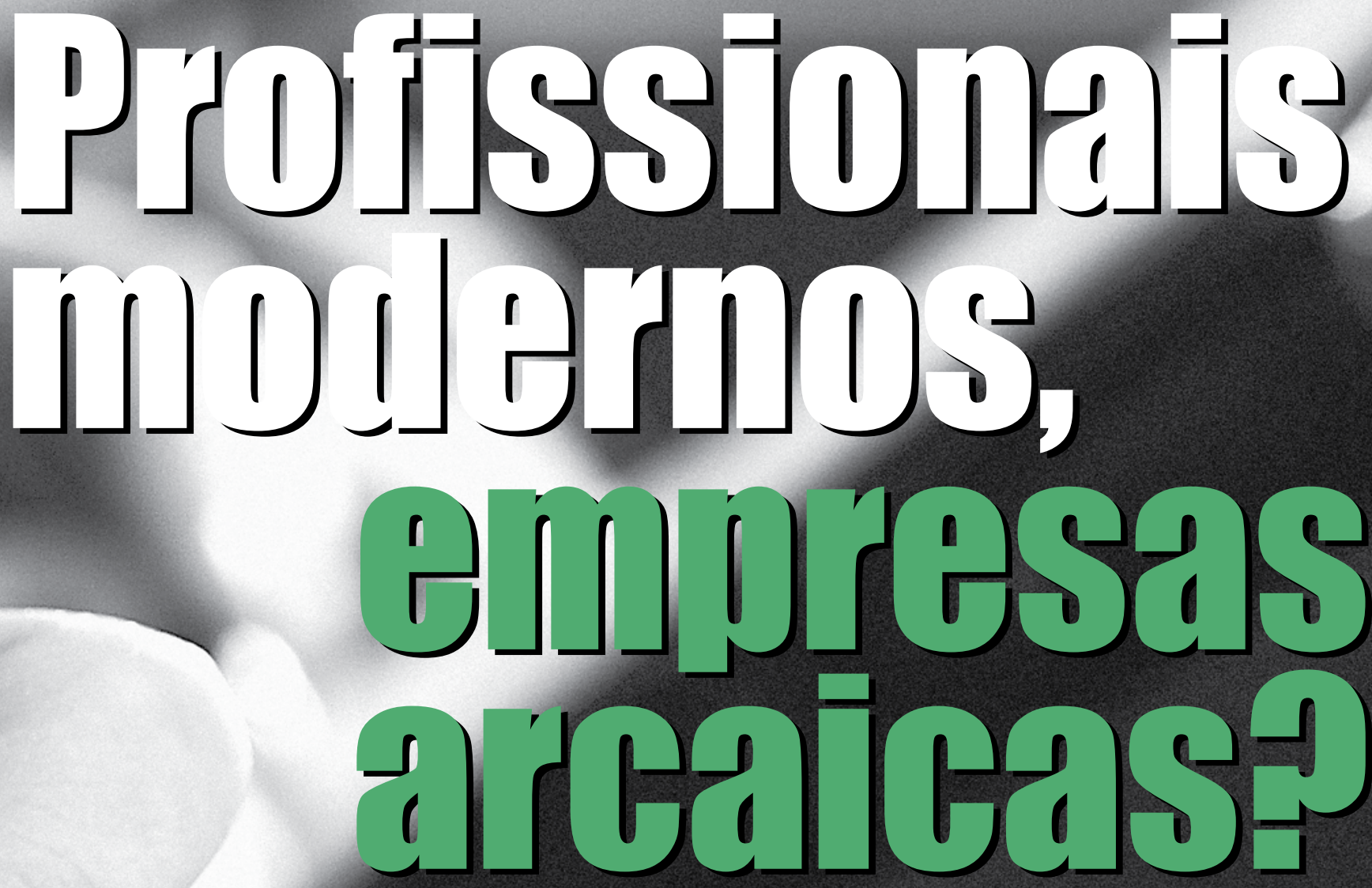

As empresas exigem de seus profissionais o desenvolvimento de competências cada vez mais complexas, mas, na prática, elas mesmas acabam não aproveitando seus talentos. Ainda encontramos empresas com práticas arcaicas e ultrapassadas de gestão de pessoas POR ANDERSON DE SOUZA SANTA'ANNA 


\section{Profissionais modernos, empresas arcaicas?}

As pressões em torno da competitividade, a intensificação dos processos de globalização e as profundas transformações nas estruturas dos mercados evidenciam a relevância de as organizações reverem seus modelos e instrumentos de gestão, em particular os direcionados ao gerenciamento de seus elementos humanos.

$\mathrm{Na}$ medida em que fontes tradicionais de vantagem competitiva, tais como tecnologia e mão-de-obra barata, não mais se revelam suficientes para proverem uma posição competitiva sustentável, os indivíduos e suas competências passam a ser enfatizados como elementos centrais de diferenciação estratégica.

Contudo, este artigo, baseado em uma pesquisa recente com 1.003 alunos de graduação e pós-graduação executiva em administração e pósgraduação executiva em telecomunicações (ver Raio X), mostra que a difusão do discurso que faz apelo à valorização dos trabalhadores e à necessidade de competências cada vez mais abrangentes e sofisticadas não tem sido acompanhada, no mesmo nível, por uma modernidade de políticas e práticas de gestão capaz de propiciar um ambiente organizacional favorável ao desenvolvimento e aplicação das competências requeridas.

DEFININDO COMPETÊNCIAS. O conceito de competência não é recente. Na verdade, constitui uma idéia consideravelmente antiga. Ela, no entanto, foi resgatada no presente em decorrência de fatores como os processos de reestruturação produtiva em curso, a intensificação das descontinuidades e imprevisibilidades das situações econômicas, organizacionais e de mercado, e as sensíveis mudanças nas características do mercado de trabalho, resultantes, em especial, dos processos de globalização.

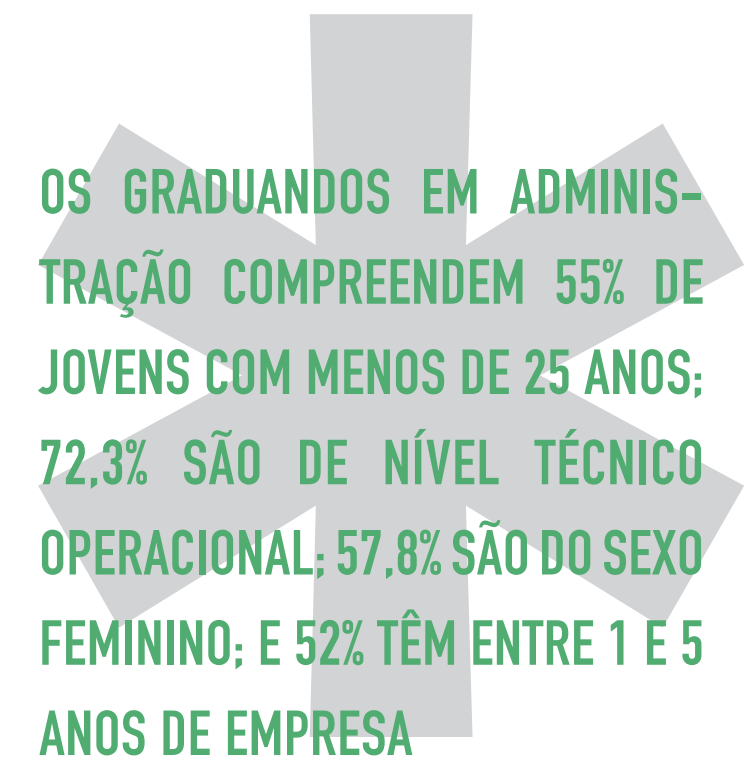

Apesar de não haver unanimidade quanto à definição de competência, as abordagens mais comuns, sobretudo no contexto acadêmico, tendem a considerá-la como uma característica ou um conjunto de características ou requisitos saberes, conhecimentos, aptidões, habilidades indicados como condição capaz de produzir efeitos de resultados ou solução de problemas.

Em levantamento realizado em nossa pesquisa, descobrimos que na atualidade 15 competências são as mais enfaticamente valorizadas pelas empresas. São elas: domínio de novos conhecimentos técnicos associados ao exercício do cargo ou função ocupada; capacidade de aprender rapidamente novos conceitos e tecnologias; criatividade; capacidade de inovação; capacidade de comunicação; capacidade de relacionamento interpessoal; capacidade de trabalhar em equipes; autocontrole emocional; visão de mundo ampla e global; capacidade de lidar com situações novas e inusitadas; capacidade de lidar com incertezas e ambigüidades; iniciativa de ação e decisão; capacidade de comprometer-se com os objetivos da organização; capacidade de gerar resultados efetivos e capacidade empreendedora. 


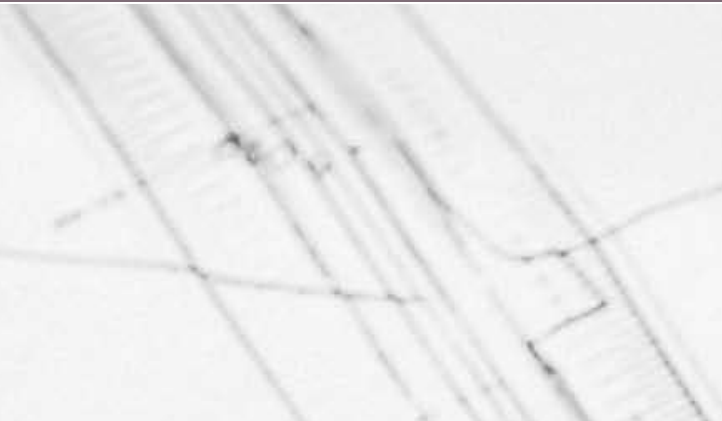

\section{RAIO X DA PESQUISA "COMPETÊNCIAS INDIVIDUAIS REQUERIDAS E MODERNIDADE ORGANIZACIONAL"}

OBJETIVO: investigar até que ponto a demanda por profissionais dotados de competências cada vez mais abrangentes e sofisticadas encontra-se acompanhada por uma evolução de políticas e práticas organizacionais que as sustentem.

T. PÚBLICO-ALVO: 654 pós-graduandos de cursos de pós-graduação executiva em administração; 220 pós-graduandos e egressos de cursos de pós-graduação executiva em telecomunicações; 129 graduandos dos últimos anos do curso de administração. A pesquisa, que faz parte de um programa de estudos direcionado à análise das relações entre competências individuais e evolução de políticas e práticas de gestão, foi realizada em Minas Gerais, compreendendo quatro levantamentos empíricos de dados, no período de 2002 a 2007. Os dados foram coletados por meio de questionários e então submetidos a tratamentos estatísticos específicos.

CARACTERÍSTICAS GERAIS DA AMOSTRA: $51,8 \%$ dos pós-graduandos em administração são jovens, ocupantes de cargo gerencial ( $41 \%)$ ou de nível técnico especializado (31\%); $51,5 \%$ são homens e $48,5 \%$ são mulheres; $45,6 \%$ têm entre 1 e 5 anos de empresa. Já os pós-graduandos em telecomunicações são ainda mais jovens ( $55 \%$ com menos de 25 anos); $72,3 \%$ ocupam cargos técnicooperacionais; $57,8 \%$ são do sexo feminino; e $52 \%$ têm entre 1 e 5 anos de empresa. Os graduandos em administração compreendem $55 \%$ de jovens com menos de 25 anos; $72,3 \%$ são de nível técnico operacional; $57,8 \%$ são do sexo feminino; e $52 \%$ têm entre 1 e 5 anos de empresa.

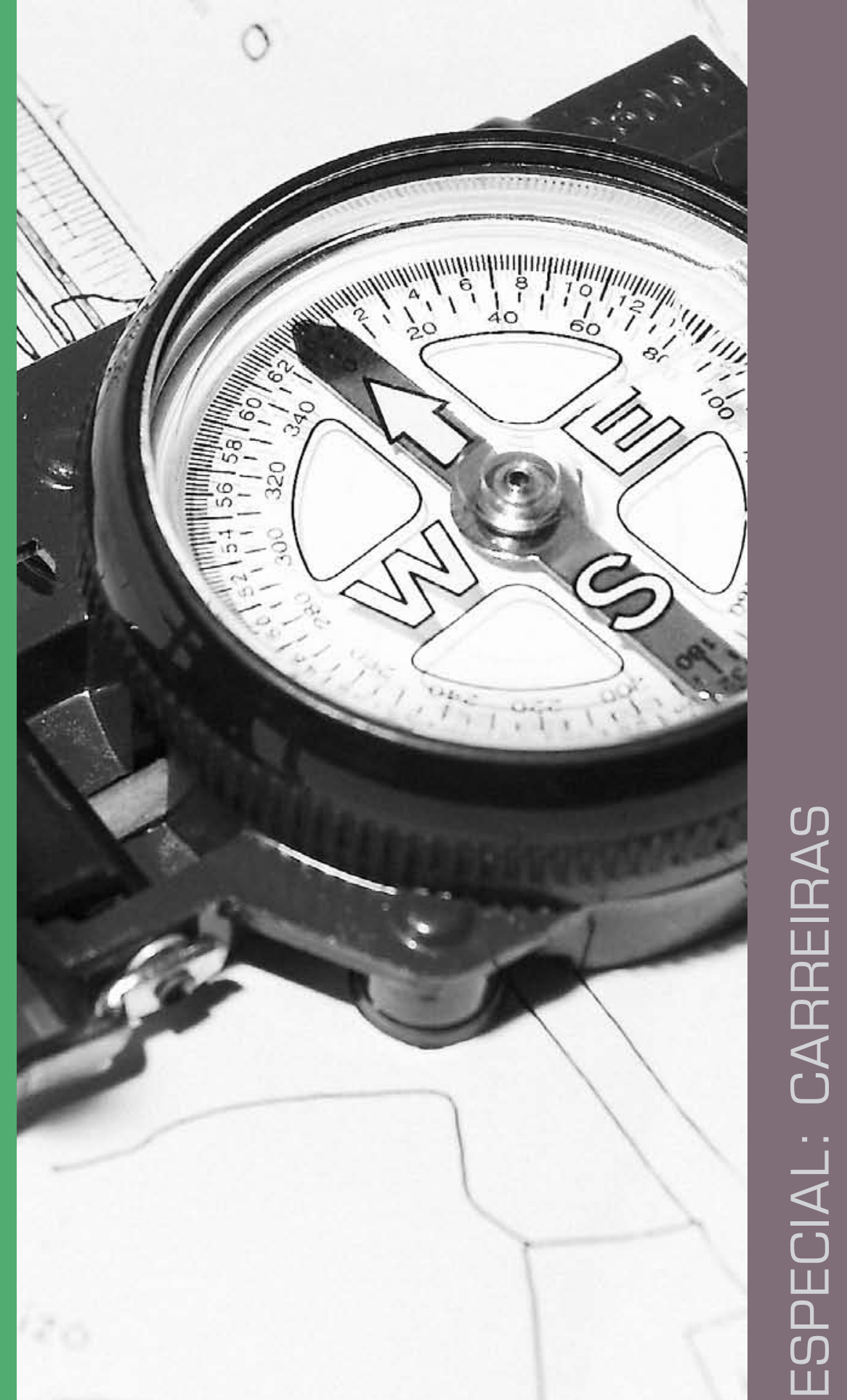




\section{Profissionais modernos, empresas arcaicas?}

MODERNIDADE ORGANIZACIONAL. Em termos organizacionais, a modernidade tem sido comumente utilizada para destacar a relevância de as empresas se prepararem para enfrentar a competição nos padrões da nova configuração do mundo dos negócios, por meio da adoção de estruturas, estratégias, políticas e práticas de gestão que favoreçam a formação de conteúdos culturais que estimulem um comportamento competente.

Assim, o grande desafio das empresas hoje é desenvolver pessoas com o perfil requerido por esse novo tipo de organização. Esse esforço exige transformar empregados de tarefas em profissionais de processos; repensar os papéis dos gestores e dos empregados nessa nova organização; reinventar os sistemas de gestão; fazer com que o aprendizado seja parte do dia-a-dia dos negócios da empresa, bem como moldar uma nova cultura que apóie as novas formas de trabalho.
$51,8 \%$ DOS PÓS-GRADUANDOS EM ADMINISTRAÇÃO SÃO JOVENS, OCUPANTES DE CARGO GERENCIAL $(41 \%)$ OU DE NÍVEL TÉCNICO ESPECIALIZADO (31\%); $51,5 \%$ SÃO HOMENS E 48,5\% SÃO MULHERES; 45,6\% TÊM ENTRE 1 E 5 ANOS DE EMPRESA
Em nossa pesquisa, consideramos como organizações da modernidade as que valorizam aspectos como a iniciativa, a responsabilidade e a liberdade de seus membros; um clima interno favorável às mudanças, inovação e aprendizagem; espírito democrático e padrões saudáveis de interação social. Além disso, outros sinais de modernidade organizacional incluem a clareza na definição de missão, objetivos, estratégias e metas; a integração entre áreas, propiciada pelo emprego de tecnologias e o estímulo a políticas e práticas que promovam a tomada de risco, a criatividade e a eficácia do desempenho das pessoas.

O CONFRONTO COM A REALIDADE. Os principais resultados de nossa pesquisa indicam que se de um lado os respondentes consideram realmente haver forte pressão, por parte das organizações em que atuam, para desenvolverem as competências profissionais por ela requeridas, de outro, eles consideram que essas mesmas organizações possuem apenas um grau moderado de modernidade.

As organizações exigem, com maior ênfase, competências diretamente relacionadas à performance organizacional, como capacidade de entrega de resultados. Outras competências percebidas como muito enfatizadas são as sociais e de relacionamento, como a capacidade de comunicação, relação interpessoal e trabalho em equipe. Há grande homogeneidade entre os respondentes quanto à percepção de que, na organização, independentemente do nível hierárquico, todos precisam dispor das mesmas competências e, não raro, em graus muito próximos.

No que diz respeito à percepção de modernidade organizacional, os respondentes aponta- 


\section{NÃO OBSTANTE A CONSTATAÇÃO DE ESTÍMULOS, POR PARTE DAS ORGANIZAÇÕES, AO ESTABELECIMENTO DE CLIMAS INTERNOS FAVO- RÁVEIS AO PROCESSO DE APRENDIZAGEM CONTíNUO, O QUE SE PERCEBE, NA PRÁtICA, É A PREVALÊNCIA DE UM CARÁTER ORGANI- ZACIONAL AINDA AUTORITÁRIO, HIERARQUIZADO E CENTRALIZADO}

ram a predominância de processos de tomada de decisão pouco participativos, transparentes e descentralizados, bem como de baixos graus de autonomia conferida a trabalhadores.

Não obstante a constatação de estímulos, por parte das organizações, ao estabelecimento de clima interno favorável ao processo de aprendizagem contínuo, e de ambiente organizacional que facilite o trabalho em equipe, o compartilhamento de informações e iniciativas de ação e decisão, o que se percebe, na prática, é a prevalência de um caráter organizacional ainda autoritário, hierarquizado e centralizado.

DISCURSO VERSUS PRÁTICA. A modernização identificada em nossa pesquisa compreende um processo que, ainda hoje, pode ser definido como de "modernização conservadora", sugerindo a necessidade de adoção, por parte das organizações, de políticas e práticas de gestão mais aderentes aos perfis profissionais requeridos por elas mesmas. Podemos dizer que as exigências de um novo perfil de trabalhador não têm sido acompanhadas por um novo conjunto de princípios, calcados na autonomia e participação dos trabalhadores nos processos decisórios.

Ao contrário, nossos resultados reforçam a necessidade de mudanças no comportamento das organizações, de modo que estruturas verticalizadas e centralizadas cedam espaço a estruturas mais horizontais e descentralizadas, favorecendo maior autonomia, participação e envolvimento dos trabalhadores, o que pressupõe mudanças profundas não só nas estruturas, nos sistemas, nas políticas e nas práticas de gestão, mas também e, principalmente, na cultura organizacional.

Ao mesmo tempo, os resultados apontam contradições entre discurso e prática de modelos de gestão em voga. Permanece, todavia, a expectativa de que, como em um círculo virtuoso, a demanda por profissionais dotados de competências cada vez mais abrangentes e sofisticadas venha a resultar em modernização das políticas e práticas de gestão capaz de propiciar ambientes organizacionais mais favorecedores ao desenvolvimento e à aplicação do máximo potencial de seus elementos humanos. 